\title{
Heart rate response to regadenoson: Making the case for its value in clinical practice
}

\author{
Efstathia Andrikopoulou, MD, ${ }^{\mathrm{a}, \mathrm{b}}$ and Fadi G. Hage, MD, FASH, FACC ${ }^{\mathrm{a}, \mathrm{b}}$ \\ ${ }^{a}$ Division of Cardiovascular Disease, University of Alabama at Birmingham, Birmingham, AL \\ b Section of Cardiology, Birmingham Veteran's Affairs Medical Center, Birmingham, AL
}

Received Aug 10, 2015; accepted Aug 10, 2015

doi: 10.1007/s12350-015-0269-2

\section{See related article, pp. 560-569}

Single-photon emission computed tomography myocardial perfusion imaging (MPI) using regadenoson as a stress agent carries a wealth of prognostic data as documented by a series of recent studies. ${ }^{1-7}$ It is, therefore, natural to pose the following questions, when reading about a novel prognostic indicator derived from regadenoson MPI ${ }^{8}$ : Is there really a need for another risk predictor in patients undergoing regadenoson MPI? Will this novel predictor add value to the information that is already available to me? In which patient populations is it useful? How will I use this in my daily clinical practice?

When clinically interpreting stress MPIs, we need to incorporate the prognostic data derived from the perfusion pattern with that derived from non-perfusion variables rather than solely focusing on the perfusion data. The value of the non-perfusion variables is evident in patients undergoing exercise stress testing. For example, functional capacity (usually expressed as exercise time on the treadmill) and the chronotropic response to exercise are strong predictors of cardiac events and overall survival. $^{9-11}$ An accumulating body of literature establishes the heart rate response (HRR) to adenosine receptor agonists as a strong prognosticator in patients undergoing

Reprint requests: Fadi G. Hage, MD, FASH, FACC, Division of Cardiovascular Disease, University of Alabama at Birmingham, Lyons Harrison Research Building 306, 1720 2nd AVE S, Birmingham, AL, 35294-0007; fadihage@uab.edu

J Nucl Cardiol 2016;23:575-80.

$1071-3581 / \$ 34.00$

Copyright (C) 2015 American Society of Nuclear Cardiology. vasodilator MPI in a manner incremental to the prognostic data derived from the perfusion pattern (Table 1). ${ }^{6,12-18}$

In this issue of the Journal, Aljaroudi et $\mathrm{al}^{8}$ extend this data by establishing the prognostic value of the HRR to regadenoson in end-stage renal disease (ESRD) patients enrolled in the ASSUAGE and ASSUAGE-CKD trials. These double-blind placebo controlled trials randomized ESRD patients referred for regadenoson MPI in a $1: 1$ ratio to receive aminophylline ( $75 \mathrm{mg}$ intravenously) or matching placebo $90 \mathrm{~s}$ after radioisotope injection. The cohort for the current analysis included the 303 patients with ESRD in these trials (age $54 \pm 12$ years, 36\% females, $56 \%$ diabetes). The authors divided the cohort using quartiles of the HRR to regadenoson from a general population referred for MPI $(>43 \%, 28-43 \%, 17-28 \%$, and $<17 \%$ ) as defined in a prior report, ${ }^{6}$ and showed that there was a stepwise increase in the risk of all-cause death and the composite outcomes of cardiac death or myocardial infarction (MI), and cardiac death, MI, or late coronary revascularization (90 days after MPI). A HRR $<28 \%$ (present in $54 \%$ of patients in the current report) was associated with a fourfold increased risk of death (hazard ratio $4.10,95 \%$ CI $1.98-8.46, P<0.0001)$ which was attenuated to threefold $(2.75,1.27-5.97, P=0.003)$ after multivariate adjustment for age, gender, diabetes, coronary artery disease, summed stress score, and left ventricular ejection fraction (LVEF). A blunted HRR was similarly associated with increased risk of the composite outcomes. The authors strengthened their argument by defining a propensity-matched cohort of 132 patients matched for 22 covariates and showing that a HRR $<28 \%$ was significantly associated with poor outcomes in this cohort and in the entire cohort after adjusting for the propensity score. Importantly, a blunted HRR was associated with increased risk in patients with normal or abnormal myocardial perfusion pattern and there was no interaction between aminophylline use, beta-blocker use, or resting heart rate and $\mathrm{HRR}$ as a determinant of outcomes. 


\section{WHY DO WE NEED ANOTHER RISK PREDICTOR IN PATIENTS UNDERGOING REGADENOSON MPI?}

As the Danish saying goes: it is difficult to make predictions, especially about the future. This is particularly relevant for risk prediction which is inherently flawed when applied to a single patient. For example, when we use any risk prediction model we divide a population into risk categories; most typically low, intermediate, and high risk. Let us assume that our patient falls into the high-risk group and that the risk for hard cardiovascular events in this group is $6 \%$ per year. ${ }^{19}$ Obviously, $94 \%$ of these patients will not have an event in the first year and around $88 \%$ will be eventfree in the first 2 years if the risk is constant over time. Alternatively, around 9 patients per 1000 in the low-risk group will have an event in the 1st year. This group of patients has an overall risk that is several-folds lower than the high-risk group, but for these 9 patients the lowrisk assignment will be of little solace. As we are currently unable to definitively predict the occurrence of cardiac events for a particular patient, we can use additional variables to refine our risk prediction models. For such a prognostic indicator to be valuable in patient management, it will need to be validated in a population of interest and shown to provide incremental value on top of currently existing prognostic models. Although a more refined risk prediction may have inherent value to the patient and provider, a more clinically useful marker will be associated with better outcomes when tied to a particular intervention. In this regards, the HRR to regadenoson satisfies the first 2 criteria but falls short on the third. Further studies are needed that explore management options based on the HRR and whether patients with a blunted or preserved HRR have superior benefit from a particular intervention.

\section{WILL THIS NOVEL PREDICTOR ADD VALUE TO THE INFORMATION THAT IS ALREADY AVAILABLE TO ME? IN WHICH PATIENT POPULATIONS IS IT USEFUL?}

As detailed above, a blunted HRR to adenosine receptor agonists has been associated with worse outcomes in a variety of studies, from independent investigators/institutions, and in distinct cohorts that span the risk continuum (Table 1). ${ }^{6,12-18}$ For example, HRR has been shown to be prognostically useful in asymptomatic patients with diabetes in the Detection of Ischemia in Asymptomatic Diabetics (DIAD) trial, ${ }^{18}$ in all-comers who have an indication for dipyridamole, ${ }^{15}$ adenosine,${ }^{16}$ or regadenoson ${ }^{6} \mathrm{MPI}$, and in patients with and without diabetes mellitus or chronic kidney disease. ${ }^{6,8,14-16}$ This prognostic data are valid in patients with and without perfusion abnormalities ${ }^{6,8,17}$ and has incremental value on top of perfusion defect size and LVEF. $^{6,12-18}$ A recent analysis of 2398 patients who underwent adenosine or dipyridamole rubidium- 82 positron emission tomography (PET) as part of the PET Prognosis Multicenter Registry extended the prognostic data provided by HRR to a patient cohort undergoing PET MPI. ${ }^{20}$

To fully appreciate the value of incorporating the HRR in clinical practice, we need to take a step back and look at the determinants of HRR. The increase of heart rate during vasodilator MPI has been shown to be mediated via direct sympathetic stimulation by adenosine A2A receptors. ${ }^{21}$ Therefore, HRR reflects the status of the autonomic nervous system and is independent of systemic vasodilation. Indeed, in both animals and humans, the intensity of the HRR has been shown to be dissociated from the systemic blood pressure response. ${ }^{22}$ It is also worth mentioning that the effect of regadenoson (and other vasodilator stress agents) on myocardial blood flow is directly related to its effect on the coronary microcirculation and independent of its hemodynamic effect. Therefore, the ability of regadenoson MPI to detect myocardial perfusion abnormalities is independent of the HRR since, unlike exercise stress, the effect of regadenoson on myocardial blood flow is uncoupled from myocardial work. ${ }^{23}$

In support of the association of HRR with cardiac autonomic dysfunction is data demonstrating a lower HRR in populations known to have cardiac autonomic dysfunction (Table 2). ${ }^{6,14-16,20,22,24}$ An analysis of 2000 patients in The Adenoscan Versus Regadenoson Comparative Evaluation for Myocardial Perfusion Imaging (ADVANCE MPI 1 and 2) Trials showed that patients with diabetes have a lower HRR to adenosine and regadenoson. ${ }^{22}$ The same is true for other patient populations that are known to have increased risk of autonomic dysfunction such as those with metabolic syndrome and kidney dysfunction. ${ }^{22,24}$ Other important predictors of a blunted HRR include advanced age, male gender, beta-blocker use, abnormal myocardial perfusion pattern, and low LVEF. ${ }^{6,15,16,20,22,24}$ Impressively, a blunted HRR independently associates with poor outcomes even after adjustments for these factors.

It is important to note that the change in heart rate in response to the different agents (adenosine, dipyridamole, regadenoson) is variable; HRR is lowest with dipyridamole and most intense with regadenoson. ${ }^{25}$ Another interesting distinction is revealed by the study of Aljaroudi et $\mathrm{al}^{8}$ In this study population that consisted exclusively of ESRD patients, the median and the quartiles of HRR were identical to the previously published distribution of HRR in 1156 consecutive 


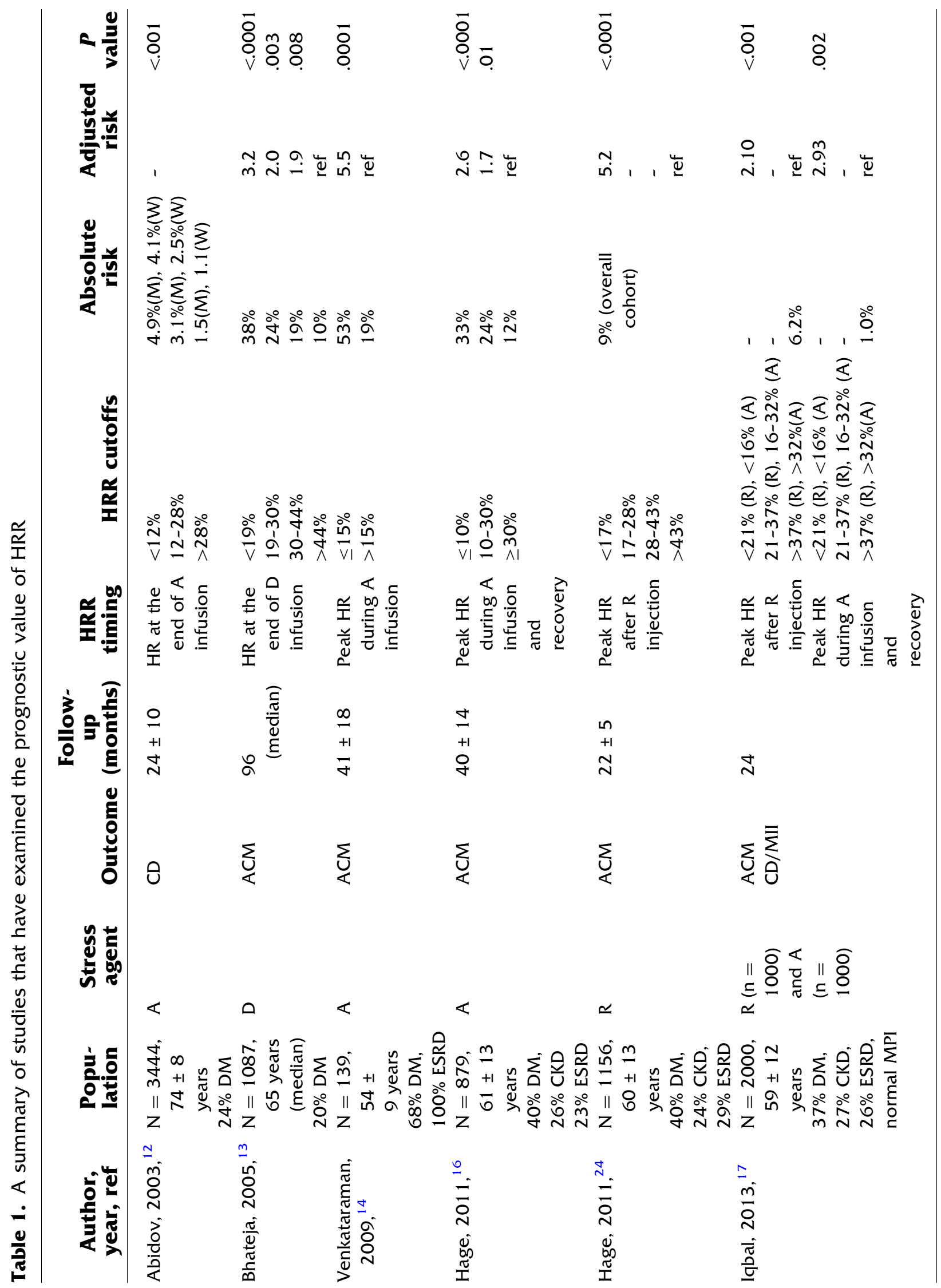


Table 2. Factors that have been associated with a blunted HRR

Advanced age

Male gender

Diabetes mellitus

Chronic kidney disease (including ESRD)

Metabolic syndrome

Hyperglycemia (irrespective of prior diagnosis of diabetes)

Beta-blocker use

Abnormal myocardial perfusion pattern (including patients with prior myocardial infarction)

Left ventricular dysfunction (low LVEF)

patients who were referred for regadenoson MPI. ${ }^{6}$ In addition to validating the findings in both reports, this indicates that patients with ESRD have a HRR to regadenoson that is not different from those with normal kidney function. Interestingly, neither CKD nor ESRD were predictors of HRR to regadenoson in the original study by our group. ${ }^{6}$ This is in contrast to the strong association of kidney function with HRR in studies that used adenosine ${ }^{16}$ or examined the data for adenosine and regadenoson combined. ${ }^{22,24}$ In fact, the HRR to adenosine was severely blunted in patients with ESRD in another cohort. ${ }^{14}$ The reasons for these differences are not clear but could be related to the decreased renal clearance of regadenoson. Irrespective of this, a blunted HRR to regadenoson remains a strong predictor of poor outcome in CKD and ESRD patients. ${ }^{6,8,14}$

\section{HOW WILL I USE THIS IN MY DAILY CLINICAL PRACTICE?}

We have previously argued that the greatest utility of HRR may be in patients with normal perfusion. ${ }^{17}$ Although the overall risk of this population is low, it is higher than the risk of patients with normal perfusion on exercise stress MPI. The addition of HRR to classical risk prediction models resulted in a net reclassification improvement in mortality of $18 \%$ and cardiac death/ nonfatal MI of $22 \%$. Further, incorporation of HRR allowed for the identification of a subgroup of patients with a risk that is comparable to normal perfusion with exercise stress. ${ }^{17}$

HRR is also prognostically important in patients with abnormal perfusion and in multi-variate models has been shown to add prognostic value on top of perfusion defect size in multiple studies. It therefore may have a role in further refining the risk in these patients in a manner similar to how transient ischemic dilation, functional capacity, or other non-perfusion variables 
are used to refine risk prediction in patients with abnormal myocardial perfusion.

Lastly, the use of HRR in clinical practice needs well-defined cutoffs for normal and abnormal HRR. As for any other continuous variable such cutoffs are artificial and therefore, as expected, vary between studies (Table 1). Importantly, HRR continues to be prognostically important when incorporated in prediction models as a continuous variable and risk appears to increase with incrementally decreasing HRR. Setting a cutoff to define a blunted HRR should take into account the distribution of HRR in the population of interest. At the same time, the categorization has to be simple to be practical for clinical use. We propose to define HRR $<15 \%$ as blunted and $>30 \%$ as normal with a HRR 15 $30 \%$ as intermediate. These cutoffs represent our opinion and are based on the cumulative data in Table 1 and will be further refined as more data become available and may be adjusted if used in populations known to have autonomic dysfunction or when different stress agents are used. We believe that the case has been made and that HRR is ready for introduction into everyday clinical use.

\section{Disclosures}

Dr Hage has received research grants from Astellas Pharma.

\section{References}

1. Hage FG, Ghimire G, Lester D, McKay J, Bleich S, El-Hajj S, et al. The prognostic value of regadenoson myocardial perfusion imaging. J Nucl Cardiol 2015; doi:10.1007/s12350-014-0050-y.

2. Iqbal FM, Hage FG, Ahmed A, Dean PJ, Raslan S, Heo J, et al. Comparison of the prognostic value of normal regadenoson with normal adenosine myocardial perfusion imaging with propensity score matching. Jacc 2012;5:1014-21.

3. Farzaneh-Far A, Shaw LK, Dunning A, Oldan JD, O'Connor CM, Borges-Neto S. Comparison of the prognostic value of regadenoson and adenosine myocardial perfusion imaging. J Nucl Cardiol 2015;. doi:10.1007/s12350-015-0155-y.

4. Bhatti S, Hakeem A, Dhanalakota S, Palani G, Husain Z, Jacobsen $\mathrm{G}$, et al. Prognostic value of regadenoson myocardial single-photon emission computed tomography in patients with different degrees of renal dysfunction. Eur Heart J Cardiovasc Imag 2014; 15:933-40.

5. El-Hajj S, AlJaroudi WA, Farag A, Bleich S, Manaoragada P, Iskandrian $\mathrm{AE}$, et al. Effect of changes in perfusion defect size during serial regadenoson myocardial perfusion imaging on cardiovascular outcomes in high-risk patients. J Nucl Cardiol 2015; doi:10.1007/s12350-015-0174-8.

6. Hage FG, Dean P, Iqbal F, Heo J, Iskandrian AE. A blunted heart rate response to regadenoson is an independent prognostic indicator in patients undergoing myocardial perfusion imaging. J Nucl Cardiol 2011;18:1086-94.
7. Lester D, El-Hajj S, Farag A, Bhambhavani P, Tauxe L, Heo J et al. Prognostic value of transient ischemic dilation with regadenoson myocardial perfusion imaging. J Nucl Cardiol 2015. doi: 10.1007/s12350-015-0272-7.

8. Aljaroudi W, Campagnoli T, Fughhi I, Wassouf M, Ali A, Doukky R. Prognostic value of heart rate response during regadenoson stress myocardial perfusion imaging in patients with end stage renal disease. J Nucl Cardiol 2015. doi:10.1007/s12350-0150234-0.

9. Kodama S, Saito K, Tanaka S, Maki M, Yachi Y, Asumi M, et al. Cardiorespiratory fitness as a quantitative predictor of all-cause mortality and cardiovascular events in healthy men and women: A meta-analysis. JAMA 2009;301:2024-35.

10. Lauer MS, Francis GS, Okin PM, Pashkow FJ, Snader CE, Marwick TH. Impaired chronotropic response to exercise stress testing as a predictor of mortality. JAMA 1999;281:524-9.

11. Azarbal B, Hayes SW, Lewin HC, Hachamovitch R, Cohen I, Berman DS. The incremental prognostic value of percentage of heart rate reserve achieved over myocardial perfusion singlephoton emission computed tomography in the prediction of cardiac death and all-cause mortality: Superiority over $85 \%$ of maximal age-predicted heart rate. J Am Coll Cardiol 2004;44:42330.

12. Abidov A, Hachamovitch R, Hayes SW, Ng CK, Cohen I, Friedman JD, et al. Prognostic impact of hemodynamic response to adenosine in patients older than age 55 years undergoing vasodilator stress myocardial perfusion study. Circulation 2003;107:2894-9.

13. Bhatheja R, Francis GS, Pothier CE, Lauer MS. Heart rate response during dipyridamole stress as a predictor of mortality in patients with normal myocardial perfusion and normal electrocardiograms. Am J Cardiol 2005;95:1159-64.

14. Venkataraman R, Hage FG, Dorfman TA, Heo J, Aqel RA, de Mattos AM, et al. Relation between heart rate response to adenosine and mortality in patients with end-stage renal disease. Am J Cardiol 2009;103:1159-64.

15. Mathur S, Shah AR, Ahlberg AW, Katten DM, Heller GV. Blunted heart rate response as a predictor of cardiac death in patients undergoing vasodilator stress technetium-99m sestamibi gated SPECT myocardial perfusion imaging. J Nucl Cardiol 2010;17:617-24.

16. Hage FG, Dean P, Bhatia V, Iqbal F, Heo J, Iskandrian AE. The prognostic value of the heart rate response to adenosine in relation to diabetes mellitus and chronic kidney disease. Am Heart J 2011;162:356-62.

17. Iqbal FM, Al Jaroudi W, Sanam K, Sweeney A, Heo J, Iskandrian $\mathrm{AE}$, et al. Reclassification of cardiovascular risk in patients with normal myocardial perfusion imaging using heart rate response to vasodilator stress. Am J Cardiol 2013;111:190-5.

18. Hage FG, Wackers FJ, Bansal S, Chyun DA, Young LH, Inzucchi SE, et al. The heart rate response to adenosine: A simple predictor of adverse cardiac outcomes in asymptomatic patients with type 2 diabetes. Int J Cardiol 2013;167:2952-7.

19. Shaw LJ, Hage FG, Berman DS, Hachamovitch R, Iskandrian A. Prognosis in the era of comparative effectiveness research: Where is nuclear cardiology now and where should it be? J Nucl Cardiol 2012;19:1026-43

20. Bellam N, Veledar E, Dorbala S, Di Carli MF, Shah S, Eapen D, et al. Prognostic significance of impaired chronotropic response to pharmacologic stress Rb-82 PET. J Nucl Cardiol 2014;21:233-44.

21. Dhalla AK, Wong MY, Wang WQ, Biaggioni I, Belardinelli L. Tachycardia caused by A2A adenosine receptor agonists is mediated by direct sympathoexcitation in awake rats. J Pharmacol Exp Ther 2006;316:695-702. 
22. Hage FG, Heo J, Franks B, Belardinelli L, Blackburn B, Wang W, et al. Differences in heart rate response to adenosine and regadenoson in patients with and without diabetes mellitus. Am Heart J 2009;157:771-6.

23. Schelbert HR. Anatomy and physiology of coronary blood flow. J Nucl Cardiol 2010;17:545-54.
24. Hage FG, Perry G, Heo J, Iskandrian AE. Blunting of the heart rate response to adenosine and regadenoson in relation to hyperglycemia and the metabolic syndrome. Am J Cardiol 2010;105:839-43.

25. Hage FG, Iskandrian AE. Heart rate response during vasodilator stress myocardial perfusion imaging: Mechanisms and implications. J Nucl Cardiol 2010;17:536-9. 